\title{
Direct hyperbilirubinemia in newborns with gastroschisis
}

\author{
Sarah B. Cairo ${ }^{1}$ Alex H. Osak ${ }^{2}$. Sara K. Berkelhamer ${ }^{2,3}$ - Cara McLaughlin ${ }^{4} \cdot$ David H. Rothstein $^{1,5}$
}

Accepted: 2 November 2018 / Published online: 10 November 2018

c) Springer-Verlag GmbH Germany, part of Springer Nature 2018

\begin{abstract}
Background Patients with gastroschisis and prolonged total (or partial) parenteral nutrition (PN) commonly develop direct hyperbilirubinemia (DH).

Objective To quantify the prevalence and severity of DH in newborns with gastroschisis and characterize the diagnostic work-up for DH in this patient population.

Design/Methods Retrospective chart review of patients born with gastroschisis between 2005 and 2015 for the first 6 months of life.

Results 29 patients were identified with gastroschisis. Mean gestational age and birthweight were $36.4( \pm 1.8)$ weeks and $2.5( \pm 0.6) \mathrm{kg} .41 \%$ were treated with primary reduction versus staged closure. Peak total and direct bilirubin (DB) levels were $10.17 \pm 6.21 \mathrm{mg} / \mathrm{dL}$ and $5.58 \pm 3.94 \mathrm{mg} / \mathrm{dL}$, respectively. 23 patients $(79.3 \%)$ were diagnosed with $\mathrm{DH}$ and $78.2 \%$ underwent additional work-up for hyperbilirubinemia consisting of imaging and laboratory studies, none of which revealed a cause for DH other than the presumed PN-associated cholestasis. In all patients, DB began to decline within 1-10 days of initiation of enteral feeds.
\end{abstract}

Conclusion(s) DH is common in patients with gastroschisis and is unlikely to be associated with pathology aside from PN. Additional work-up may lead to unnecessary resource utilization.

Levels of evidence Case series with no comparison group, Level IV.

Keywords Direct hyperbilirubinemia $\cdot$ Gastroschisis $\cdot$ Resource utilization $\cdot$ Cholestasis $\cdot$ Outcomes

\begin{tabular}{|c|c|}
\hline Abb & \\
\hline $\mathrm{PN}$ & Parenteral nutrition \\
\hline $\mathrm{CH}$ & Conjugated hyperbilirubinemia \\
\hline DB & Direct bilirubin \\
\hline
\end{tabular}

Abstract was presented in its original form at the Eastern Society for Pediatric Research Annual Meeting, Philadelphia, PA, March 24, 2017 and as a poster at the Pediatric Academic Society Annual Meeting, San Francisco, CA, May 6, 2017.

David H. Rothstein

drothstein@kaleidahealth.org

1 Department of Pediatric Surgery, John R. Oishei Children's Hospital, 1001 Main Street, Buffalo, NY 14203, USA

2 Department of Pediatrics, John R. Oishei Children's Hospital, Buffalo, USA

3 Department of Pediatrics, University at Buffalo Jacobs School of Medicine and Biomedical Sciences, Buffalo, USA

4 Department of Nutrition, John R. Oishei Children's Hospital, Buffalo, USA

5 Department of Surgery, University at Buffalo Jacobs School of Medicine and Biomedical Sciences, Buffalo, NY, USA
PNALD Parenteral nutrition associated liver disease

NASPGHAN North American Society for pediatric gastroenterology, hepatology, and nutrition

DOL Day of life

SD Standard deviation

\section{Introduction}

Cholestatic jaundice affects approximately 1 in 2500 infants and is commonly documented in neonatal intensive care (NICU) patients [11, 36]. Elevation of direct bilirubin levels (DB) may result from hepatobiliary dysfunction and be indicative of serious illness or pathology $[11,34]$. Diagnostic criteria for direct hyperbilirubinemia (DH) vary, with DB that is $>2 \mathrm{mg} / \mathrm{dL}$ or accounts for greater than $20 \%$ of the total bilirubin after 2 weeks of life commonly cited [27, 31]. The most recent recommendations from North American Society for Pediatric Gastroenterology, Hepatology, and Nutrition (NASPGHAN), however, define abnormal as a 
serum $\mathrm{DB}>1.0 \mathrm{mg} / \mathrm{dL}$ (or $>17 \mathrm{umol} / \mathrm{L}$ ) [11]. NASPGHAN provides recommendations for evaluation of cholestatic jaundice in infants but does not specifically address the management of patients who are ill or who have coexisting, possibly confounding, conditions.

While work up is not performed on all infants with DH, the differential diagnosis is broad including both obstructive and intrinsic processes $[13,39,41]$. Obstructive causes, including biliary atresia, account for $20-30 \%$ of cases in full-term neonates. Intrinsic processes include infection, metabolic disease, endocrine abnormalities and autoimmune processes. Clinical practice guidelines published by NASPGHAN and updated in 2017 based on literature review and expert opinion include differentiation between direct bilirubinemia and total bilirubinemia with other laboratory studies frequently employed to help define the etiology and severity of DH [22, 39]. Parenteral nutrition associated liver disease (PNALD) is a common cause of neonatal cholestasis, present in up to $20 \%$ of neonates receiving parenteral nutrition (PN) for greater than 2 weeks [20]. PNALD is frequently observed after the first 2 weeks of PN or later [14]. In studies evaluating congenital or surgical anomalies, an incidence of PNALD up to $25-85 \%$ is reported in neonates with intestinal failure requiring prolonged PN $[8,9]$. The estimated incidence of PNALD is higher in children than adults and frequently occurs along with a primary gastrointestinal disorder causing intestinal failure and prolonged need for PN (congenital intestinal abnormalities, necrotizing enterocolitis, etc.).

Major risk factors for PNALD include prematurity, low birthweight, early and prolonged exposure to parenteral nutrition, infection, and insufficient use of the gastrointestinal tract, many of which are present in the setting of gastroschisis, a common congenital abdominal wall defect [25, 38]. The average patient with gastroschisis undergoes surgical intervention within the first few hours of life and receives an average of 2-3 weeks of PN, with gradual advancement of enteral feeds [2]. In contrast to other neonates with $\mathrm{DH}$, there is limited literature on a specific relationship between gastroschisis and DH including the utility of additional diagnostic work up for these patients.

The primary objectives of this study were to describe the incidence and degree of DH in neonates with gastroschisis, according to the 2017 NASPGHAN definition, and determine the frequency and yield of diagnostic workup.

\section{Methods}

The study protocol and use of electronic medical records were reviewed by the Institutional Review Board of the State University of New York, University at Buffalo and need for informed consent was waived (UB IRB: 00001120).

\section{Data source}

We performed a retrospective review of neonates at a single institution in Western New York. Medical records including Cerner Powerchart, the primary electronic medical record employed by the NICU to capture vital signs, laboratory and imaging results, and consultant documentation and Neodata, a complementary multi-user data system purpose-designed for NICU care to assist in daily patient management from admission through discharge, were utilized.

\section{Case selection}

Neonatal patients at the Women and Children's Hospital of Buffalo with a diagnosis of gastroschisis based on ICD-9 and 10 codes between January 1, 2005 and December 31, 2015 were identified for inclusion. Patients with and without diagnosis of DH were included in the study for comparison purposes where DH was defined using the NASPGHAN guidelines of a serum direct bilirubin $>1 \mathrm{mg} / \mathrm{dL}$. Those patients with an initial direct bilirubin $>1.0$ who normalized before 2 weeks were placed in the non-cholestatic group.

A variety of patient demographic and clinical variables were included in the analysis. Outcomes of interest included the duration of PN administration, day of feeding initiation and time to full enteral nutrition, trends in total and conjugated bilirubin, length of stay (LOS) and studies or evaluations performed as part of a diagnostic work-up for DH. Workup and findings were collected from the first 6 months of life.

\section{Statistical analysis}

A retrospective descriptive analysis of the data was performed. Categorical variables were compared using the Pearson's Chi-squared and Fisher's exact test, with Student's $t$ test for continuous variables. All statistical analyses were performed using Excel and IBM SPSS Statistics Software 24. Where possible based on limitations in data availability and skewing, data are represented as mean and standard deviation or median and interquartile range.

\section{Results}

\section{Patient demographics}

A total of 30 patients were identified with diagnosis of gastroschisis confirmed on chart review. Of these, 24 patients were found to have a serum direct bilirubin greater than $1 \mathrm{mg} / \mathrm{dL}$ within first 6 months of life (but after the first 2 
weeks of life), for an overall incidence of $\mathrm{DH}$ of $79.3 \%$ using the NASPGHAN definition The gestational age, birth weight and gender distribution in the DH and nonDH cohorts were comparable (Table 1). While there was no significant difference in average birth weight percentile, patients with DH were noted to have a statistically significantly lower discharge weight percentile (9.6th percentile for $\mathrm{DH}, 37.0$ th percentile for patients without $\mathrm{DH}, p<0.001$ ). The percentile change was also statistically significantly different between the two groups with an average decline of $23.2 \pm 20.6$ for patients with DH and an average increase in weight percentile of $2.0 \pm 33.9$ for patients without $\mathrm{DH}$ $(p=0.03)$.
Specific patient characteristics related to surgical procedure and intensive unit care were evaluated as a proxy for illness severity. On average, there was no difference in the likelihood of ventilator use or duration of time on the ventilator at $10.7 \pm 11.2$ days for patients with $\mathrm{DH}$ and $7.3 \pm 8.2$ days for patients without $(p=0.53)$. With regard to complications associated with gastroschisis, there was no significant difference in the incidence of intestinal atresia, necrosis or perforation, need for bowel resection, and need for stoma creation between the two groups. Type of procedure was also comparable with the majority of patients undergoing silo placement for an average of $9.2 \pm 7.3$ days. There was no significant difference in the type of repair performed overtime.
Table 1 Characteristics of patients with gastroschisis

\begin{tabular}{|c|c|c|c|c|}
\hline & Patients with DH & Patients without DH & Total & $p$ value $^{\mathrm{b}}$ \\
\hline Total, $n(\%)$ & $23(79.3)$ & $6(20.7)$ & 29 & \\
\hline \multicolumn{5}{|l|}{ Gender $(\%)$} \\
\hline Male & $10(71.4)$ & $4(28.6)$ & $14(48.3)$ & 0.31 \\
\hline Female & $13(86.7)$ & $2(13.3)$ & $15(51.7)$ & \\
\hline \multicolumn{5}{|l|}{ Birth weight } \\
\hline Average, kg (SD) & $2.45(0.6)$ & $2.72(0.5)$ & $2.50(0.6)$ & 0.33 \\
\hline Birth weight percentile (SD) & $29.8(22.5)$ & $35.0(18.0)$ & $30.7(21.6)$ & 0.61 \\
\hline Discharge weight percentile (SD) & $9.6(6.5)$ & $37.0(27.2)$ & $11.8(17.8)$ & $<0.001$ \\
\hline Change weight percentile (SD) & $-23.2(20.6)$ & $+2.0(33.9)$ & $-18.9(24.7)$ & 0.03 \\
\hline \multicolumn{5}{|l|}{ Gestational age } \\
\hline Average, weeks (SD) & $36.22(1.8)$ & $36.91(1.8)$ & $36.36(1.8)$ & 0.41 \\
\hline \multicolumn{5}{|l|}{ Ventilator use $(\%)$} \\
\hline At time of delivery & $7(30.4)$ & $2(33.3)$ & $9(31.0)$ & 1.00 \\
\hline Following Procedure & $22(95.7)$ & $4(66.7)$ & $26(89.7)$ & 0.10 \\
\hline Time on ventilator, days (SD) & $10.68(11.2)$ & $7.33(8.2)$ & $9.96(11.2)$ & 0.53 \\
\hline \multicolumn{5}{|l|}{ Type of procedure $(\%)$} \\
\hline Primary reduction & $10(43.5)$ & $2(33.3)$ & $12(41.4)$ & 0.39 \\
\hline Silo placement, no reduction & $13(56.5)$ & $4(66.7)$ & $17(58.6)$ & \\
\hline Duration silo usage, days (SD) & $9.85(8.1)$ & $7.25(4.0)$ & $9.24(7.3)$ & 0.55 \\
\hline \multicolumn{5}{|l|}{ Associated intestinal complications (\%) } \\
\hline Bowel matting & $3(13.0)$ & $0(0.0)$ & $3(10.3)$ & 0.49 \\
\hline Atresia & $2(8.7)$ & $0(0.0)$ & $2(6.9)$ & 0.62 \\
\hline Necrosis, perforation & $7(30.4)$ & $1(16.7)$ & $8(27.6)$ & 0.08 \\
\hline Bowel resection & $8(34.8)$ & $1(16.7)$ & $9(31.0)$ & 0.38 \\
\hline Stoma creation & $3(13.0)$ & $1(16.7)$ & $4(13.8)$ & 0.63 \\
\hline Any bowel related complication & $10(43.5)$ & $1(16.7)$ & $11(37.9)$ & 0.23 \\
\hline \multicolumn{5}{|l|}{ NICU related complications (\%) } \\
\hline Urinary tract infection & $5(22.0)$ & $0(0.0)$ & $5(17.0)$ & 0.55 \\
\hline Central line-associated sepsis & $8(34.0)$ & $1(16.7)$ & $9(31.0)$ & 0.39 \\
\hline Any infectious complication & $13(56.5)$ & $1(16.7)$ & $14(48.3)$ & 0.08 \\
\hline \multicolumn{5}{|l|}{ Length of stay } \\
\hline Average length of stay, days (SD) & $82.5(40.9)$ & $64.2(37.0)$ & $79.34(40.3)$ & 0.36 \\
\hline
\end{tabular}

${ }^{\text {a }}$ Direct hyperbilirubinemia defined per NASPGHAN guidelines as direct bilirubin after 2 weeks of age of $>1.0 \mathrm{mg} / \mathrm{dL}$ or $>17 \mathrm{mmol} / \mathrm{L}$

${ }^{\mathrm{b}}$ Fisher's exact test for binary results, ANOVA for continuous variable 
Coexisting infections were evaluated with no significant difference in the rate of urinary tract infections $(22.0 \%$ in patients with $\mathrm{DH}, 0$ in patients without, $p=0.55$ ) or central line-associated sepsis (34.0\% in patients with $\mathrm{DH}, 16.0 \%$ in patients without, $p=0.39$ ). The average length of stay (LOS) was longer for patients with $\mathrm{DH}$ at $82.5 \pm 40.9$ days compared to $64.2 \pm 37$ days for patients without $\mathrm{DH}$, although the difference was not statistically significant $(p=0.36)$.

\section{Nutritional characteristics}

There were no significant differences in nutritional practices between the two groups despite variability within the cohort as a whole. Patients with DH remained on PN for an average of 59.7 days (median 54, IQR 35-74), started enteral feeds on day of life 31.6 (median 25, IQR 17.8-35.3) and were on full feeds by day of life 64.2 (median 54, IQR 24.3-78.8) (Table 2). Patients without DH remained on PN for an average of 42.0 days (median 31, IQR 18-56), started enteral feeds on day 17.8 (median 19, IQR 13-27), and were on full feeds by day 43.2 (median 31, IQR 23-56), none of which are statistically significantly different from patients with DH. Average caloric intake and use of low-lipid formulation, defined as $1 \mathrm{gm} / \mathrm{kg}$ per week, was not different between the groups. Similarly, percentage of hospital stay on any PN, average calories from PN, and average weight gain did not differ significantly between the two groups. Weight gain in grams per day was lower but not significantly so for patients with DH compared to those without DH (average $18.8 \pm 4.5 \mathrm{~g}$ versus average $20.0 \pm 8.9 \mathrm{~g}$, respectively; $p=0.66)$. Similarly, changes in zscore for weight, and length (but not head circumference) were more negative for patients with DH but again without statistical significance $(p=0.21$ and $p=0.31$, respectively).

\section{Assessment and Management of Cholestasis}

Cholestasis was first observed, on average, on DOL 17.9 (range, DOL 2-38). The first DB recorded above the threshold of $1 \mathrm{mg} / \mathrm{dL}$ is denoted as "First abnormal DB." The DB peaked, on average, on day 50.3 (range, DOL 20-101) at $6.48 \pm 3.9 \mathrm{mg} / \mathrm{dL}$. Three patients from the original cohort of 29 patients had a rise in DB within the first week of life which normalized within this week and did not reach the two

Table 2 Nutritional information for neonates with gastroschisis

\begin{tabular}{|c|c|c|c|c|}
\hline & Patients with DH $(20)^{\mathrm{a}}$ & Patients without DH (6) & Total (26) & $p$ value $^{\mathrm{b}}$ \\
\hline Total days on $\mathrm{PN}^{\mathrm{c}}$, median (IQR) & $54(35,74)$ & $31(18,56)$ & $53(31.3,74.0)$ & 0.97 \\
\hline Day of life enteral feeds initiated, median (IQR) & $25(17.8,35.3)$ & $19(13,27)$ & $24(17,30)$ & 0.07 \\
\hline Day of life PN started, average (SD) & $1.3(0.7)$ & $1.2(0.4)$ & $1.3(0.7)$ & 0.74 \\
\hline Days until full feeds, median (IQR) & $54(24.3,78.8)$ & $31(23,56)$ & $54(31.0,77.5)$ & 0.21 \\
\hline \multicolumn{5}{|l|}{ Low lipid formulation used, $n(\%)^{\mathrm{d}}$} \\
\hline Yes & $12(60.0)$ & $2(33.3)$ & $14(53.8)$ & \multirow[t]{2}{*}{0.49} \\
\hline No & $8(40.0)$ & $4(66.7)$ & $12(46.2)$ & \\
\hline Day low lipid formulation started, average (SD) & $28.0(13.4)$ & $14.0(\mathrm{n} / \mathrm{a})$ & $26.3(13.4)$ & 0.37 \\
\hline \multicolumn{5}{|l|}{ Initial enteral formula, $n(\%)$} \\
\hline Breast milk & $7(30.4)$ & $1(16.7)$ & $8(27.6)$ & \multirow[t]{5}{*}{0.23} \\
\hline Breast milk, fortified & $1(4.3)$ & $1(16.7)$ & $2(6.9)$ & \\
\hline Formula (with breast milk) & $8(34.8)$ & $2(33.3)$ & $10(34.5)$ & \\
\hline Formula (without breast milk) & $3(13.0)$ & $1(16.7)$ & $4(13.8)$ & \\
\hline Malabsorptive formula & $4(17.4)$ & $1(16.7)$ & $5(17.2)$ & \\
\hline Average caloric intake, kcal/kg/day (SD) & $95.6(8.6)$ & $97.2(7.3)$ & $96.0(8.2)$ & 0.68 \\
\hline Average $\%$ days on any PN (SD) & $82.7(18.1)$ & $75.1(23.0)$ & $81.0(19.1)$ & 0.40 \\
\hline Average $\%$ calories from PN (SD) & $73.0(19.6)$ & $58.2(18.4)$ & $69.6(20.0)$ & 0.11 \\
\hline Average weight gain, g/day (SD) & $18.8(4.5)$ & $20.0(8.9)$ & $19.1(5.6)$ & 0.66 \\
\hline Average weight gain, g/kg/day (SD) & $6.2(2.0)$ & $7.5(2.3)$ & $6.5(2.1)$ & 0.19 \\
\hline Change zscore (weight), median (IQR) & $-1.3(-1.8,-0.7)$ & $-0.8(-1.0,-0.6)$ & $-1.2(-1.8,-0.7)$ & 0.21 \\
\hline Change zscore (head circumference), median (IQR) & $0.2(-1.0,0.5)$ & $0(-0.1,0.1)$ & $0.1(-0.7,0.5)$ & 0.77 \\
\hline Change zscore (length), median (IQR) & $-1.5(-2.3,0.0)$ & $-0.6(-1.2,0.4)$ & $-1.2(-2.1,0.1)$ & 0.31 \\
\hline
\end{tabular}

${ }^{\mathrm{a}}$ Complete nutrition, weight data available for $100 \%$ patients without DH (6 of 6), 87\% of patients with DH (20 of 23)

${ }^{\mathrm{b}}$ Fisher's exact test and Pearson Chi-squared for categorical variables, ANOVA for continuous variables

${ }^{c} \mathrm{PN}$ : total or partial parenteral nutrition

${ }^{\mathrm{d}}$ Total number of patients on low lipid formulation not equal to total on PN due to missing or unavailable data at the time of review 
week threshold suggested in the NASPGHAN guidelines (1). These patients were not included in the analysis of DH and per chart review, were felt to represent the population of newborns with physiologic jaundice peaking and resolving within the first $96 \mathrm{~h}$ of life and not requiring additional diagnostic evaluation (Bhutani et al., 2013).

$60 \%$ of the 23 patients with DH were treated with on choleretic medications or specialized lipid formulations including Ursodiol alone (34.5\%), Phenobarbital alone (17.4\%), Ursodiol and Phenobarbital (4.3\%), or Sincalide, (a cholecystokinin-octapeptide) and Omegaven ${ }^{\mathrm{TM}}$ (a fish oilbased lipid emulsion containing omega-3 fatty acids) (4.3\%) (Table 3). Follow-up until normalization of DB was only available for $65.2 \%$ of patients; when available, DB normalized, on average, by DOL 110.8 (range, DOL 38-365). Of patients without documentation of normalization of DB, 11 were discharged from the hospital with an elevated DB but on a downward trajectory.

Of the patients with DH, 18 (78.2\%) underwent additional diagnostic work up (Table 4). Evaluation was limited to septic work up with blood and urine cultures in 7 of these patients. A right upper quadrant ultrasound was performed on $11(61 \%)$ of patients, at a mean DOL of 48 , demonstrating a normal gallbladder in $3(27 \%)$, and findings suggesting contracted gallbladder, biliary sludge, and non-visualization of the gallbladder in the remaining patients. Hepatobiliary Scintigraphy (HIDA scan) was initially ordered for 5 (21.7\%) patients with DH but canceled for three patients due to improving DB. Of the HIDA scans performed, one was normal and one was significant for adequate radiotracer uptake in liver but non-visualization of radiotracer activity in intestines. The latter study was reportedly suboptimal due to excessive blood pool activity resulting in a high background activity; the patient subsequently underwent repeat ultrasound consistent with gallbladder ghost. In the setting of normalizing labs, however, no further work up or gastroenterology follow-up was performed. Metabolic, endocrine, and infectious work ups were also performed to evaluate for associated anomalies that may contribute to DH including thyroid studies, amino acid analysis, alpha-1 antitrypsin deficiency, and work up for parvo virus, EBV, CMV, hepatitis, and toxoplasmosis, all of which were normal (Table 4). There was no significant difference in rate of urinary tract infections ( $17 \%$ overall) or central line-associated sepsis ( $31 \%$ overall) between the patients with $\mathrm{DH}$ and patients without $\mathrm{DH}$ (Table 1). No liver biopsies were performed in this cohort.
Table 3 Detailed assessment and management of direct hyperbilirubinemia $(n=23)$

\begin{tabular}{|c|c|c|c|}
\hline & Mean & Standard deviation & Range \\
\hline Day of first reported $\mathrm{DB}^{\mathrm{a}}$ & 6.9 & 4.1 & $2-18$ days \\
\hline First DB & 0.97 & 0.83 & $0.3-3.6 \mathrm{mg} / \mathrm{dL}$ \\
\hline $\mathrm{DOL}^{\mathrm{b}}$ when $\mathrm{DB}$ is first abnormal ${ }^{\mathrm{c}}$ & 17.9 & 9.5 & 2-38 days \\
\hline First abnormal DB (mg/dL) & 1.71 & 0.74 & $1.1-3.9 \mathrm{mg} / \mathrm{dL}$ \\
\hline DOL at peak DB & 50.3 & 20.7 & 20-101 days \\
\hline Peak DB $(\mathrm{mg} / \mathrm{dL})$ & 6.48 & 3.92 & $1.7-15.4 \mathrm{mg} / \mathrm{dL}$ \\
\hline Peak TB $(\mathrm{mg} / \mathrm{dL})^{\mathrm{d}}$ & 9.59 & 6.63 & $3.0-25.0 \mathrm{mg} / \mathrm{dL}$ \\
\hline DOL DB normalized & 110.8 & 78.3 & 38-365 days \\
\hline DOL enteral feeds started & 31.6 & 19.3 & $7-88$ \\
\hline DOL parenteral nutrition discontinued & 62.8 & 31.8 & $22-133$ days \\
\hline DOL medication started ${ }^{\mathrm{e}}$ & 50.9 & 22.2 & 11-103 days \\
\hline Medication given, $n(\%)$ & $14(60.0)$ & & \\
\hline Ursodiol & $8(34.5)$ & & \\
\hline Phenobarbital & $4(17.4)$ & & \\
\hline Ursodiol and phenobarbital & $1(4.3)$ & & \\
\hline Omegaven and Sincalide & $1(4.3)$ & & \\
\hline
\end{tabular}

Direct hyperbilirubinemia $=$ serum direct bilirubin $>1 \mathrm{mg} / \mathrm{dL}$ after first 2 weeks of life

${ }^{a} \mathrm{DB}$ : direct bilirubin $(\mathrm{mg} / \mathrm{dL})$

${ }^{b}$ DOL: day of life from birth

${ }^{c}$ Elevated DB defined as direct bilirubin $>1.0 \mathrm{mg} / \mathrm{dL}$ when the total bilirubin is $<5$ or $\mathrm{DB}>20 \%$ of the total when TB is $>5$

${ }^{\mathrm{d}} \mathrm{TB}$ : total bilirubin $(\mathrm{mg} / \mathrm{dL})$

${ }^{\mathrm{e}}$ Day of life medication started for conjugated hyperbilirubinemia. 34.5\% Ursodiol (Actigall) alone. 17.4\% Phenobarbital alone. 21.7\% Ursodiol and Phenobarbital. 4.3\% Phenobarbital and Actigall. 4.3\% ADEK vitamin supplement and Actigall. 4.3\% Sincalide and Omegaven. 17.4\% with conjugated hyperbilirubinemia not started on medication 
Table 4 Diagnostic work up in patients with direct hyperbilirubinemia (total $n=23$ )

\begin{tabular}{|c|c|c|c|}
\hline Test performed & $\begin{array}{l}\text { Number (\% of patients } \\
\text { with DH) }\end{array}$ & $\begin{array}{l}\text { Average DOL test } \\
\text { performed }\end{array}$ & Results, comments $(n)$ \\
\hline Right upper quadrant ultrasound & $11(47.8)$ & 47.8 & $\begin{array}{l}\text { Normal gallbladder, common bile duct (3) } \\
\text { Contracted gallbladder (3) } \\
\text { Sludge in gallbladder (4) } \\
\text { Gallbladder not visualized (1) }\end{array}$ \\
\hline Hepatobiliary Scintigraphy (HIDA scan) & $5(21.7)$ & 48 & $\begin{array}{l}\text { Canceled due to improved direct hyper- } \\
\text { bilirubinemia (3) } \\
\text { Normal anatomy and excretion patterns } \\
\text { (1) } \\
\text { Inconclusive results (1) }\end{array}$ \\
\hline Metabolic work up ${ }^{\mathrm{a}}$ & $2(8.6)$ & 68 & Normal results (2) \\
\hline Endocrine work up ${ }^{\mathrm{b}}$ & $2(8.6)$ & 49.5 & Normal results (2) \\
\hline Infectious work up ${ }^{c}$ & $4(17.3)$ & 65 & Normal results (2) \\
\hline
\end{tabular}

${ }^{a}$ Metabolic work up: amino acid analysis, alpha-1 antitrypsin deficiency

${ }^{\mathrm{b}}$ Endocrine work up: thyroid function studies

${ }^{c}$ Infectious work up: hepatitis screening, toxoplasmosis, parvovirus, EBV, CMV

\section{Discussion}

Gastroschisis, a congenital anomaly involving failure of the abdominal wall to fully mature has a low prevalence of associated congenital anomalies or genetic abnormalities [28]. Additionally, neonates with gastroschisis are frequently full-term and with normal birthweight, such that the primary risk factor for prolonged intravenous nutrition is the ileus secondary to amniotic fluid contacting the intestines and to a lesser degree, the risk of necrotizing enterocolitis, elevated intraabdominal pressure, and need for bowel resection [1, 12, 25; Miranda da Silva 25]. Early cholestasis can be identified in almost 1 of every 50 NICU patients but typically resolves spontaneously and is not always associated with structural or functional etiologies $[7,10,27]$. Though limited to a single institution and modest sample size, our data supports that prolonged use of total (or partial) parenteral nutrition (PN) in patients with gastroschisis is associated with high rates of cholestasis or conjugated hyperbilirubinemia. In comparison to previous series published by Fallon et al., the rate of DH observed in this study is slightly higher, which is likely associated with variable definitions of $\mathrm{DH}$ and later initiation of enteral feeds [10]. Interestingly, total PN days in the DH cohort did not vary from the non-DH cohort, suggesting that there may be as-yet unidentified confounders that mitigate the pejorative cholestatic effects of PN.

In a 2015 systematic review, the most common etiologies of DH identified in newborn patients included idiopathic neonatal hepatitis $(26.0 \%)$, extrahepatic biliary atresia (25.9\%), infection (11.5\%) and PN associated cholestasis (6.4\%) [13]. Due to the non-specific lab finding of DH and high morbidity of delayed diagnosis of biliary atresia or anatomical cause of laboratory derangement, patients with $\mathrm{DH}$ often undergo a wide range of tests before reaching a diagnosis. Tests performed often include abdominal ultrasound, HIDA scan, percutaneous cholangiogram and a variety of laboratory studies to evaluate for metabolic, endocrine, and infectious etiologies [18]. Screening algorithms have been proposed to exclude biliary atresia but, as noted, no predictive models specific to patients with gastroschisis have been described. This study demonstrated a wide variety of diagnostic tests being performed without any pathologic diagnoses or identification of conditions other than parenteral nutrition associated liver disease (PNALD), consistent with the low incidence of reported anatomical or alternative diagnoses in the literature. As noted, patients with gastroschisis often require prolonged $\mathrm{PN}$ due to intestinal dysmotility prohibiting the provision of adequate enteral nutrition [16]. In this study, although the incidence of central line-associated sepsis was higher in the group diagnosed with $\mathrm{DH}$, this was not statistically significant $(p=0.39)$.

The discussion of DH in patients with gastroschisis is additionally complicated by the lack of a unifying or consistent diagnosis of PNALD, which in many cases is a diagnosis of exclusion. The patients in this study all demonstrated resolution of DH without findings to suggest a surgically-correctable, mechanism cause for DH (such as biliary atresia).

There was no significant difference in average gestational age or birth weight percentile, but patients with DH were noted to have a statistically significantly lower discharge weight percentile and average decline in weight percentile from birth to discharge compared to an increase in weight percentile in patients without DH $(p=0.03)$. In a cohort of patients with gastroschisis evaluated by Fallon et al., younger gestational age and cholestasis were found to be independently associated with compromised growth [10]. 
Prolonged exposure to PN and delay in enteral nutrition are thought to contribute to poor weight gain and cholestasis via intestinal villous atrophy, increased mucosal permeability and bacterial translocation [6, 35]. While Fallon et al. found increased duration of $\mathrm{PN}$ and increased incidence of DH with silo placement compared to the primary closure of the abdominal wall defect, we did not observe this in our patients. Silo placement and peri-operative fluid administration might artificially increase body weight early in the post-natal period. This likely altered the rate of weight gain/ growth and may have disproportionately impacted sicker patients requiring more aggressive fluid resuscitation. When examining weight gain per day, the proportional weight gain $(\mathrm{gm} / \mathrm{kg} / \mathrm{day})$ did not differ between patients with and without DH. Measuring gestationally-adjusted weight percentiles at a consistent and later post-natal age may be a more accurate measure of growth. Another potential explanation for the overall difference in weight gain in patients with DH which is currently being explored with regard to fat-soluble vitamin deficiencies and milk protein intolerance is the increased intestinal permeability in the setting of hyperbilirubinemia $[17,30,33]$.

Just as there is documented inconsistency in the diagnostic workup for $\mathrm{DH}$, there is variability in this study, as well as the literature, in the management of PNALD. $60 \%$ of patients in this study who were diagnosed with $\mathrm{DH}$ were started on choleretic medications with variable involvement of gastroenterologists. Interestingly, direct bilirubin peaked, on average, within a week of starting medication and initiating diagnostic work up. Based on the improvement in DB in patients with and without medication, small sample size, and timing of peak DB, no correlation or causation can be inferred from these data. For patients started on choleretic medications and those that were not, the day DB is noted to normalize is within 1-2 days of discontinuing PN. There was no significant difference, however, between days until enteral nutrition was initiated and patient was tolerating full feeds between patients who were and were not started on choleretic medications. In a larger series of patients with PNALD, Ursodiol therapy was not found to be associated with duration of PNALD [38]. Sincalide (an analogue of the C-terminal octapeptide) and phenobarbital (an inductor of bile excretion and bilirubin conjugation) have both been suggested for diagnostic and therapeutic purposes in the management of functional biliary disorders. While both agents are associated with improved accuracy and diagnostic yield of cholescintigraphy, data demonstrating improvement in PNALD are limited and inconsistent [23, 29, 40].

In contrast to pharmacologic interventions, adjustments to administration of parenteral nutrition have been shown to be associated with improved outcomes and decreased duration of PNALD. Early nutrition of any form is associated with improved outcomes and decreased hospital length of stay in neonates with a more significant effect by enteral nutrition $[14,15,32]$. The fat component, or lipid emulsion, in parenteral nutrition has been identified as a potential causative factor for PNALD making adjustments in lipid administration, a common strategy for prevention and treatment of PNALD [19, 24, 26].

With regards to the quantity and type of lipid emulsion administered, $27.6 \%$ of all patients in this study were placed on a "low-lipid" formulation at $1 \mathrm{gm} / \mathrm{kg} / \mathrm{d}$ for a week or more but did not differ significantly between patients with DH and without $(p=0.46)$. This is consistent with dosing recommendations for the prevention of PNALD in the absence of other risk factors such as sepsis or intestinal bacterial overgrowth [10]. Omega-6 polyunsaturated fatty acids (PUFAs) in soybean oil-based lipid emulsions are known to be pro-inflammatory and contribute to the development of hepatotoxicity. Omegaven (Fresenius Kabi AG, Bad Homburg, Germany) is a fish-oil based product high in omega-3 fatty acids which is frequently administered in Europe for patients receiving prolonged $\mathrm{PN}$ for its hepatoprotective, anti-inflammatory effects and improvements in jaundice and liver function tests [4, 37]. Only one patient in the present study received Omegaven; causality of improvement in DB, however, cannot be determined based on the natural history of patients with gastroschisis and concurrent introduction of enteral feeds. Given the relatively small sample size, however, we are unable to definitively state why low lipid formulation may have been started earlier in patients without DH than those with $\mathrm{DH}$. We speculate that, as is the case at many institutions, there is variability secondary to provider preferences as well as a shift towards and away from the prophylactic administration of low lipid formulations in patients deemed at high risk for PNALD.

Interpretation of these results should be done with caution as delay in diagnosis of biliary atresia or other causes of $\mathrm{DH}$ can be devastating in the neonatal population. Lee et al. describe an unfortunate case of concurrent biliary atresia and gastroschisis in a patient who developed jaundice after the transition to enteral feeds and discharge from the hospital [21]. Extrahepatic biliary atresia is the leading cause for liver transplantation in the pediatric population and incredibly rare in the setting of gastroschisis. While Lee et al. suggest that a vascular insult may result in both defects, the presentation of jaundice after transition to enteral nutrition makes the diagnosis of PNALD incredibly unlikely and ultimately describes a very different and unfortunate patient population than evaluated in the present study [3].

\section{Limitations}

Based on the moderately low incidence of gastroschisis and direct hyperbilirubinemia, this study has several limitations. This is a retrospective study of a single institution 
with a relatively small sample size, as noted and, therefore, results must be interpreted and applied with caution by encouraging larger institutions and collaborative networks to continue this investigation. Despite only being conducted at one institution, this study shed light on considerable amounts of variability between providers. There was variation in timing of initiation of enteral feeds, rate of feed advancement, work up, and use of choleretic medications. With neonatologists, surgeons, dieticians, and other ancillary staff involved in each patient's care, highly variable practice patterns were observed. Additionally, physician practice pattern variability contributes to timing of blood work during hospital stay such that the first recorded abnormal DB may not be a perfect representation of day in which DB actually became abnormal or began to rise. For most of the patients in the study, however, the duration of time between last normal DB and first abnormal DB was comparable.

Another major limitation of this study is the lack of a control group. Several populations were considered as potential controls because of prolonged exposure to parenteral nutrition and delayed enteric feeds. Despite broad use of parenteral nutrition, there are no other congenital anomalies associated with as significant and predictable of an ileus as gastroschisis without associated anomalies. In review of the literature to identify the incidence of PNALD in neonates on prolonged parenteral nutrition without gastroschisis, for example, additional risk factors for cholestatic liver dysfunction (beyond the use of parenteral nutrition) limit comparability to this otherwise well-studied population. One mechanism to account for the lack of control group would be to compare patients with gastroschisis to all patients admitted to the neonatal intensive care unit who meet the NASPGHAN criteria. While we anticipate a large number of confounders and contributing variables which may need to be accounted for in statistical analysis, with adequate sample size (as may be obtained through a multiinstitutional collaborative), this may be possible.

\section{Conclusions}

Transient and marked DH is nearly universal among patients born with gastroschisis and does not appear to be associated with pathologic diagnoses other than PNALD. Prolonged PN use is likely to have a variable effect on DH in this population. It may be appropriate to delay DH workup in patients with gastroschisis beyond a typical period.

Funding This research did not receive any specific grant from funding agencies in the public, commercial, or not-for-profit sectors.

\section{Compliance with ethical standards}

Ethical approval All procedures performed in studies involving human participants were in accordance with the ethical standards of the institutional and/or national research committee and with the 1964 Helsinki declaration and its later amendments or comparable ethical standards.

Informed consent The need for informed consent was waived by the Institutional Review Board as the study was felt to pose less than minimal risk by its nature as a retrospective review.

\section{References}

1. Akgür FM, Ozdemir T, Olguner M, Aktuğ T, Ozer E (1998) An experimental study investigating the effects of intraperitoneal human neonatal urine and meconium on rat intestines. Res Exp Med (Berl) 198(4):207-213

2. Aljahdali A, Mohajerani N, Skarsgard ED, (CAPSNet), CPSN (2013) Effect of timing of enteral feeding on outcome in gastroschisis. J Pediatr Surg 48(5):971-976. https://doi.org/10.1016/j. jpedsurg.2013.02.014

3. Atkison PR, Ross BC, Williams S, Howard J, Sommerauer J, Quan D, Wall W (2002) Long-term results of pediatric liver transplantation in a combined pediatric and adult transplant program. CMAJ 166(13):1663-1671

4. Beath S, Kelly D (2016) Total parenteral nutrition-induced cholestasis: prevention and management. 20(1):159-176. https://doi. org/10.1016/j.cld.2015.08.009

5. Bhutani VK, Stark AR, Lazzeroni LC, Poland R, Gourley GR, Kazmierczak S (2013) Predischarge screening for severe neonatal hyperbilirubinemia identifies infants who need phototherapy. J Pediatr 162(3):477-482.e471. https://doi.org/10.1016/j.jpeds .2012.08.022

6. Buchman AL, Moukarzel AA, Bhuta S, Belle M, Ament ME, Eckhert CD,... . Vijayaroghavan SR (1995) Parenteral nutrition is associated with intestinal morphologic and functional changes in humans. JPEN 19(6):453-460. https://doi.org/10.1177/01486 07195019006453

7. Chou SC, Palmer RH, Ezhuthachan S, Newman C, Pradell-Boyd B, Maisels MJ, Testa MA (2003) Management of hyperbilirubinemia in newborns: measuring performance by using a benchmarking model. Pediatrics 112(6 Pt 1):1264-1273

8. Diamanti A, Basso MS, Castro M, Calce A, Pietrobattista A, Gambarara M (2007) Prevalence of life-threatening complications in pediatric patients affected by intestinal failure. Transplant Proc 39(5):1632-1633. https://doi.org/10.1016/j.transproce ed.2007.02.083

9. Diamond IR, de Silva N, Pencharz PB, Kim JH, Wales PW (2007) Neonatal short bowel syndrome outcomes after the establishment of the first Canadian multidisciplinary intestinal rehabilitation program: preliminary experience. J Pediatr Surg 42(5):806-811. https://doi.org/10.1016/j.jpedsurg.2006.12.033

10. Fallon EM, Mitchell PD, Potemkin AK, Nehra D, Arsenault DA, Robinson EM, Puder M (2012) Cholestasis and growth in neonates with gastroschisis. J Pediatr Surg 47(8):1529-1536. https:// doi.org/10.1016/j.jpedsurg.2011.12.028

11. Fawaz R, Baumann U, Ekong U, Fischler B, Hadzic N, Mack CL, Karpen SJ (2017) Guideline for the evaluation of cholestatic jaundice in infants: joint recommendations of the North American Society for pediatric gastroenterology, hepatology, and nutrition and the european society for pediatric gastroenterology, hepatology, and nutrition. J Pediatr Gastroenterol Nutr 64(1):154-168. https://doi.org/10.1097/MPG.0000000000001334 
12. Gonzalez DO, Cooper JN, Peter SDS, Minneci PC, Deans KJ (2017) Variability in outcomes after gastroschisis closure across U.S. children's hospitals. J Pediatr Surg. https://doi.org/10.1016/j. jpedsurg.2017.04.012

13. Gottesman LE, Vecchio DMT, Aronoff SC (2015) Etiologies of conjugated hyperbilirubinemia in infancy: a systematic review of 1692 subjects. BMC Pediatr 15:192. https://doi.org/10.1186/s1288 7-015-0506-5

14. Guglielmi FW, Regano N, Mazzuoli S, Fregnan S, Leogrande G, Guglielmi A, Francavilla A (2008) Cholestasis Induced by Total Parenteral Nutrition. 12(1), 97-110. https://doi.org/10.1016/j. cld.2007.11.004

15. Gulack BC, Laughon MM, Clark RH, Burgess T, Robinson S, Muhammad A, Smith PB (2016) Enteral feeding with human milk decreases time to discharge in infants following gastroschisis repair. J Pediatr 170:85-89. https://doi.org/10.1016/j.jpeds 2015.11.046

16. Howat JM, Wilkinson AW (1970) Functional intestinal obstruction in the neonate. Arch Dis Child 45(244):800-804

17. Indrio F, Raimondi F, Laforgia N, Riezzo G, Polimeno L, Francavilla R (2007) Effect of hyperbilirubinemia on intestinal permeability in healthy term newborns. Acta Paediatr 96(1):73-75. https ://doi.org/10.1111/j.1651-2227.2006.00007.x

18. Jancelewicz T, Barmherzig R, Chung C, Ling S, Kamath B, Ng V, Langer J (2015) A screening algorithm for the efficient exclusion of biliary atresia in infants with cholestatic jaundice. 50(3), 363-370. https://doi.org/10.1016/j.jpedsurg.2014.08.014

19. Jensen AR, Goldin AB, Koopmeiners JS, Stevens J, Waldhausen JH, Kim SS (2009) The association of cyclic parenteral nutrition and decreased incidence of cholestatic liver disease in patients with gastroschisis. J Pediatr Surg 44(1):183-189. https://doi. org/10.1016/j.jpedsurg.2008.10.033

20. Lauriti G, Zani A, Aufieri R, Cananzi M, Chiesa PL, Eaton S, Pierro A (2014) Incidence, prevention, and treatment of parenteral nutrition-associated cholestasis and intestinal failure-associated liver disease in infants and children: a systematic review. JPEN J Parenter Enteral Nutr 38(1):70-85. https://doi.org/10.1177/01486 07113496280

21. Lee TC, Barshes NR, Nguyen L, Karpen SJ, Quiros-Tejeira RE, Carter BA, Goss JA (2005) Gastroschisis and biliary atresia in a neonate: uncommon presentation or common precipitant. Eur J Pediatr Surg 15(6):434-436. https://doi.org/10.1055/s-2005-87292

22. Lu FT, Wu JF, Hsu HY, Ni YH, Chang MH, Chao CI, Chen HL (2014) $\gamma$-Glutamyl transpeptidase level as a screening marker among diverse etiologies of infantile intrahepatic cholestasis. J Pediatr Gastroenterol Nutr 59(6):695-701. https://doi. org/10.1097/MPG.0000000000000538

23. Majd M, Reba RC, Altman RP (1981) Effect of phenobarbital on $99 \mathrm{mTc}$-IDA scintigraphy in the evaluation of neonatal jaundice. Semin Nucl Med 11(3):194-204

24. Messing B, Pontal PJ, Bernier JJ (1983) Metabolic study during cyclic total parenteral nutrition in adult patients with and without corticosteroid-induced hypercatabolism: comparison with standard total parenteral nutrition. JPEN 7(1):21-25. https://doi. org/10.1177/014860718300700121

25. Alves FMDS, Miranda ME, Aguiar MJBD, Viana MCFB (2016) Nutritional management and postoperative prognosis of newborns submitted to primary surgical repair of gastroschisis. J Pediatr (Rio J) 92(3):268-275. https://doi.org/10.1016/j.jped.2015.07.009

26. Moss RL, Amii LA (1999) New approaches to understanding the etiology and treatment of total parenteral nutrition-associated cholestasis. Semin Pediatr Surg 8(3):140-147
27. Moyer V, Freese DK, Whitington PF, Olson AD, Brewer F, Colletti RB (2004) North American Society for Pediatric Gastroenterology, H. p. a. Guideline for the evaluation of cholestatic jaundice in infants: recommendations of the North American Society for Pediatric Gastroenterology, Hepatology and Nutrition. J Pediatr Gastroenterol Nutr 39(2):115-128 N.

28. Overcash RT, DeUgarte DA, Stephenson ML, Gutkin RM, Norton ME, Parmar S, Schrimmer DB (2014) Factors associated with gastroschisis outcomes. Obstet Gynecol 124(3):551-557. https:// doi.org/10.1097/aog.0000000000000425

29. Poddar U, Bhattacharya A, Thapa BR, Mittal BR, Singh K (2004) Ursodeoxycholic acid-augmented hepatobiliary scintigraphy in the evaluation of neonatal jaundice. J Nucl Med 45(9):1488-1492

30. Raimondi F, Indrio F, Crivaro V, Araimo G, Capasso L, Paludetto R (2008) Neonatal hyperbilirubinemia increases intestinal protein permeability and the prevalence of cow's milk protein intolerance. Acta Paediatr 97(6):751-753. https://doi.org/10.111 1/j.1651-2227.2008.00746.x

31. Rangel S, Calkins C, Cowles R, Barnhart D, Huang E, Abdullah F, Teitelbaum D (2012) Parenteral nutrition-associated cholestasis: an American Pediatric Surgical Association Outcomes and Clinical Trials Committee systematic review. 47(1), 225-240. https:// doi.org/10.1016/j.jpedsurg.2011.10.007

32. Salama GS, Kaabneh MA, Almasaeed MN, Alquran MI a (2015) Intravenous lipids for preterm infants: a review. Clin Med Insights Pediatr 9:25-36. https://doi.org/10.4137/CMPed.S21161

33. Samra NM, Abrak EE, Dash SEl, Raziky HH,ESaidE, M., \& Sheikh E, M. A (2018) Evaluation of vitamin D status bone mineral density and dental health in children with cholestasis. Clin Res Hepatol Gastroenterol 42(4):368-377. https://doi. org/10.1016/j.clinre.2017.11.010

34. Satrom K, Gourley G (2016) Cholestasis in Preterm Infants. Clin Perinatol 43(2):355-373. https://doi.org/10.1016/j. clp.2016.01.012

35. Sax HC, Illig KA, Ryan CK, Hardy DJ (1996) Low-dose enteral feeding is beneficial during total parenteral nutrition. Am J Surg 171(6):587-590

36. Sloane AJ, Nawab US, Carola D, Aghai ZH (2017) Utility of measuring direct bilirubin at first $72 \mathrm{~h}$ of age in neonates admitted to the neonatal intensive care unit. J Perinatol 37(5):536-540. https://doi.org/10.1038/jp.2016.259

37. Strang BJ, Reddix BA, Wolk RA (2016) Improvement in parenteral nutrition-associated cholestasis with the use of Omegaven in an infant with short bowel syndrome. Nutr Clin Pract 31(5):647653. https://doi.org/10.1177/0884533616643697

38. Thibault M, McMahon J, Faubert G, Charbonneau J, Malo J, Ferreira E, Mohamed I (2014) Parenteral nutrition-associated liver disease: a retrospective study of ursodeoxycholic acid use in neonates. https://doi.org/10.5863/1551-6776-19.1.42

39. Ullah S, Rahman K, Hedayati M (2016) Hyperbilirubinemia in neonates: types, causes, clinical examinations, preventive measures and treatments: a narrative review article. Iran J Public Health 45(5):558-568

40. Ziessman HA (2009) Interventions used with cholescintigraphy for the diagnosis of hepatobiliary disease. Semin Nucl Med 39(3):174-185. https://doi.org/10.1053/j.semnuclmed .2008.12.002

41. İpek M, Aydın M, Zencıroğlu A, Gökçe S, Okumuş N, Gülaldı NC (2013) Conjugated hyperbilirubinemia in the neonatal intensive care unit. Turk J Gastroenterol 24(5):406-414 